\author{
Robert ZARZYCKI ${ }^{1}$ \\ Rafał KOBYŁECKI ${ }^{2}$ \\ Marcin KRATOFIL ${ }^{3}$ \\ Damian PAWLOWSKI ${ }^{4}$ \\ Zbigniew BIS ${ }^{5}$
}

\title{
TWORZENIE I REDUKCJA TLENKU AZOTU W WARUNKACH OXYSPALANIA
}

\begin{abstract}
$\mathrm{W}$ artykule przedstawiono proces tworzenia i redukcji tlenku azotu w warunkach zbliżonych do charakterystycznych dla procesu oxyspalania. Dokonano analizy przebiegów czasowych zmian zawartości $\mathrm{NO}$ oraz $\mathrm{CO}_{2} \mathrm{i} \mathrm{O}_{2}$ w spalinach w trakcie utleniania paliwa oraz określono warunki sprzyjające redukcji zawartości NO $\mathrm{w}$ gazach dolotowych. Ustalono, że w zakresie temperatur $750-950^{\circ} \mathrm{C}$ przy spalaniu w powietrzu (stan odniesienia) nie następuje tworzenie się termicznych tlenków azotu. Wyniki uzyskane dla różnych składów gazów w otoczeniu płonących ziaren paliwa wykazały ponadto, że w pewnych warunkach jest możliwa wyraźna, dochodząca do $10 \%$, redukcja zawartości NO w odniesieniu do jego zawartości w gazie dolotowym. Wyniki badań oznaczania zawartości azotu w próbkach popiołu po spaleniu wykazały śladowe zawartości $\mathrm{N}$ (w przypadku wszystkich badanych próbek zawartość azotu $<0,01 \%$ ), potwierdzając, że podczas spalania azot zawarty w węglu przechodzi w całości do fazy gazowej.
\end{abstract}

Słowa kluczowe: oxyspalanie, przedpalenisko cyklonowe, tlenek azotu

\section{Wstęp}

Jedną z przyczyn występujących na świecie zmian klimatycznych, powodujących m.in. wzrost temperatury, są produkty powstałe podczas spalania paliw kopalnych, takich jak $\mathrm{CO}_{2}, \mathrm{SO}_{2}, \mathrm{NO}_{x}$ i pyły. W ostatnim okresie prowadzi się wiele badań nad opracowaniem technologii zero-emisyjnych procesów konwersji energii z paliw kopalnych. Jednym z nich jest wdrożenie technologii oxyspalania do istniejących i nowo budowanych jednostek energetycznych. Oxyspala-

\footnotetext{
${ }^{1}$ Autor do korespondencji/corresponding author: Robert Zarzycki, Politechnika Częstochowska, ul. Brzeźnicka 60a, 42-200 Częstochowa, Polska, tel.: (34) 3257334, wew. 18, e-mail: zarzycki @ is.pcz.czest.pl

${ }^{2}$ Rafał Kobyłecki, Politechnika Częstochowska, e-mail: rafalk@is.pcz.czest.pl

${ }^{3}$ Marcin Kratofil, Politechnika Częstochowska, e-mail: mkratofil@is.pcz.czest.pl

${ }^{4}$ Damian Pawłowski, Politechnika Częstochowska, e-mail: dpawlowski@is.pcz.czest.pl

${ }^{5}$ Zbigniew Bis, Politechnika Częstochowska, e-mail: zbis@is.pcz.czest.pl
} 
nie paliw kopalnych ułatwia realizację procesu CCS, którego zadaniem jest wychwyt dwutlenku węgla ze spalin, np. na potrzeby jego podziemnego składowania. Wprowadzenie technologii oxyspalania wraz z procesem CCS rozpatruje się zarówno dla kotłów pyłowych, jak i fluidalnych, opalanych węglem brunatnym oraz kamiennym. Proces oxyspalania może być realizowany przez wzbogacanie powietrza w dodatkowy udział tlenu, tak aby zwiększyć zawartość tlenu w powietrzu powyżej $21 \%$, lub przez całkowite wyeliminowanie $\mathrm{z}$ utleniacza azotu ,Z powietrza”. W drugim przypadku istnieje konieczność zastapienia strumienia azotu „, powietrza” innym strumieniem gazów, w celu zapewnienia odpowiedniej aerodynamiki w komorze spalania oraz nośnika strumienia ciepła. W tym przypadku stosuje się recyrkulację spalin, które składają się głównie z $\mathrm{CO}_{2}$, pary wodnej oraz tlenu, a także z pewnych ilości $\mathrm{SO}_{2}$ i $\mathrm{NO}_{x}$. Spaliny te mogą także zawierać w swoim składzie pewien udział azotu, wynikający głównie ze strumienia wprowadzanego utleniacza o założonej czystości $\mathrm{O}_{2}$.

Proces spalania paliw kopalnych wiąże się $\mathrm{z}$ emisją zanieczyszczeń w postaci $\mathrm{SO}_{2}$ oraz $\mathrm{NO}_{x}$. Źródłem tlenków azotu może być azot zawarty w powietrzu - powstają wtedy tlenki termiczne oraz szybkie. Źródłem tlenków azotu jest także azot zawarty w paliwie. W przypadku realizacji procesu oxyspalania główną przyczyną powstawania tlenków azotu jest zawartość azotu w paliwie.

\section{Badania konwersji azotu paliwowego}

Badania prowadzono na specjalnie zaadaptowanym stanowisku laboratoryjnym (rys. 1.) w wybranych temperaturach: 750,850 oraz $950^{\circ} \mathrm{C}$ dla syntetycznych spalin skomponowanych z różnych udziałów $\mathrm{CO}_{2}(10,20$ i $50 \%)$, $\mathrm{O}_{2}(10,20$ i $30 \%)$, NO (100, 200 i $\left.300 \mathrm{ppm}\right)$, argonu oraz przegrzanej pary wodnej w ilości 15\% obj. Skład spalin syntetycznych odpowiadał warunkom rzeczywistym występującym w przedpalenisku cyklonowym [1-3].

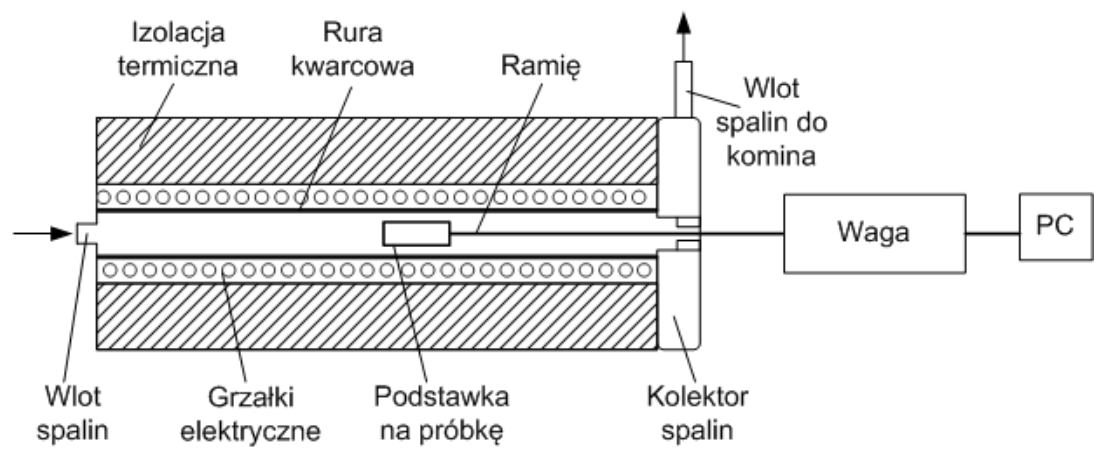

Rys. 1. Schemat stanowiska laboratoryjnego

Fig. 1. Schematic of laboratory stand 
Organizacja przepływu na stanowisku laboratoryjnym umożliwiała niezakłóconą przepływem gazów obserwację próbki oraz pomiar spalin opuszczających układ. Zasadniczą część stanowiska stanowił piec, z umieszczoną centralnie rurą kwarcową o długości $1 \mathrm{~m}$, otoczoną grzałką elektryczną i izolacją. Do wnętrza pieca doprowadzano syntetyczne spaliny, których skład ustalano przed każdym pomiarem i utrzymywano w trakcie badań na zadanym poziomie. Przed doprowadzaniem do stanowiska poszczególne składniki spalin mieszano w mieszalniku zabudowanym $\mathrm{w}$ strefie wlotowej pieca. Piec zapewniał możliwość pracy $\mathrm{w}$ zakresie temperatur $<1050^{\circ} \mathrm{C}, \mathrm{z}$ dokładnością regulacji temperatury $\pm 2^{\circ} \mathrm{C}$. Próbkę paliwa umieszczano na podstawce ramienia posiadającego otwór pozwalający na ciągłą rejestrację składu gazów w sąsiedztwie spalanej próbki. Następnie badana próbka paliwa była wprowadzana do wnętrza pieca przez przemieszczenie za pomocą układu jezdnego.

Próbka spalanego paliwa była umieszczana na porowatej wełnie mineralnej, znajdującej się na suporcie. Próbkę o znanej masie początkowej (ok. 0,1-0,5 g) umieszczano w taki sposób, aby zapewnić równomierną dyspersję ziaren paliwa. Przygotowaną próbkę wprowadzano do rozgrzanego pieca, rejestrując zmiany składu spalin w trakcie procesu spalania. Po spaleniu pozostałość stałą wyjmowano $\mathrm{z}$ pieca i niezwłocznie umieszczano w eksykatorze do ostygnięcia. Następnie przy użyciu analizatora Leco CHNS Truspec oznaczano zawartość azotu w próbce.

W badaniach wykorzystano 3 wybrane rodzaje paliwa (węgiel kamienny oraz grafit) o parametrach przedstawionych $w$ tab. 1. i 2. Granulacja spalanego paliwa wynosiła poniżej $100 \mu \mathrm{m}$. Wyniki zamieszczone w tab. 1. i 2. wskazuja, że parametry węla są typowe dla paliw stosowanych w energetyce zawodowej. Różnice dotyczą przede wszystkim wartości opałowej (w stanie suchym prawie $18 \mathrm{MJ} / \mathrm{kg}$ dla węgla $\mathrm{nr} 1 \mathrm{oraz}$ ponad $22 \mathrm{MJ} / \mathrm{kg} \mathrm{w}$ przypadku węgla $\mathrm{nr} 2$ ), jak również zawartości popiołu (znacznie wyższa w przypadku węgla $\mathrm{nr} 1$ ) oraz siarki (odpowiednio 0,91 i 1,65\% w przypadku węgla nr 1 i nr 2). Zawartość azotu w obu węglach była zbliżona i mieściła się w zakresie ok. 0,9-1,0\%.

W celu ustalenia i porównania wpływu spalania pozostałości koksowej (zawierającej znikomą ilość części lotnych) na tworzenie NO z azotu zawartego w fazie gazowej przeprowadzono również badania spalania grafitu. Paliwo to (jak wykazują wyniki z tab. 1. i 2.) składa się głównie z pierwiastka $\mathrm{C} w$ postaci stałej - zawartość części lotnych w stanie suchym nie przekracza 1,2\%.

Tabela 1. Zestawienie wyników analizy technicznej badanych paliw

Table 1. Results of proximate analysis of the tested fuels

\begin{tabular}{|c|c|c|c|c|c|c|}
\hline \multirow{2}{*}{ Rodzaj paliwa } & $\mathbf{W}_{\text {tot }}$ & $\mathbf{W}_{\mathbf{P}}$ & $\mathbf{W}_{\mathbf{H}}$ & $\mathbf{V M}^{\mathbf{d}}$ & $\mathbf{A}^{\mathbf{d}}$ & $\mathbf{F C}^{\mathbf{d}}$ \\
\cline { 2 - 7 } & \multicolumn{7}{|c|}{$\%$} \\
\hline Węgiel nr 1 & 8,0 & 6,3 & 1,9 & 25,7 & 26,9 & 47,3 \\
\hline Węgiel nr 2 & 17,1 & 9,2 & 8,7 & 27,6 & 16,8 & 55,6 \\
\hline Grafit & - & - & 0,09 & 1,2 & 3,7 & 95,1 \\
\hline
\end{tabular}


Tabela 2. Zestawienie wyników analizy elementarnej badanych paliw

Table 2. Results of ultimate analysis of the tested fuels

\begin{tabular}{|c|c|c|c|c|c|c|c|c|}
\hline \multirow{2}{*}{ Rodzaj paliwa } & $\mathbf{C}^{\mathbf{d}}$ & $\mathbf{H}^{\mathbf{d}}$ & $\mathbf{N}^{\mathbf{d}}$ & $\mathbf{S}^{\mathbf{d}}$ & $\mathbf{O}^{\mathbf{d}}$ & $\mathbf{H H V}^{\mathbf{d}}$ & $\mathbf{L H V}^{\mathbf{d}}$ \\
\cline { 2 - 8 } & \multicolumn{6}{|c|}{$\%$} & \multicolumn{2}{|c|}{$\mathbf{M J} / \mathbf{k g}$} \\
\hline Węgiel nr 1 & 64,5 & 4,3 & 1,02 & 0,91 & 2,3 & 18,83 & 17,73 \\
\hline Węgiel nr 2 & 60,2 & 4,1 & 0,93 & 1,65 & 16,3 & 23,61 & 22,24 \\
\hline Grafit & 99,0 & 0,6 & 0,18 & 0 & 0,22 & 32,35 & - \\
\hline
\end{tabular}

\section{Wyniki badań i ich analiza}

W ramach badań dokonano analizy wpływu temperatury oraz zawartości $\mathrm{NO}, \mathrm{O}_{2}, \mathrm{CO}_{2}$ i pary wodnej w spalinach na proces tworzenia i redukcji NO podczas spalania wybranych próbek węgla i grafitu w warunkach zbliżonych do oxyspalania w przedpalenisku cyklonowym. Zestawienie wybranych wyników badań przedstawiono na rys. 2-5. Czasowe przebiegi zmian stężeń wybranych gazów (rys. 2.) potwierdzają (wykazane również w pracy [4]) opóźnienie w wychodzeniu azotu zawartego w paliwie podczas jego spalania: maksimum emisji NO następuje zwykle po kilkunastu sekundach po zarejestrowaniu maksimum zawartości $\mathrm{CO}_{2}$ i odpowiadającej mu minimalnej zawartości tlenu w spalinach. Wyniki te potwierdzają ponadto istotny wpływ rodzaju paliwa na poziom emisji NO. W przypadku spalania grafitu (rys. 2.), który właściwie nie zawiera części lotnych i azotu, emisja NO jest równa zeru, co potwierdza pośrednio, że w danych warunkach nie następuje tworzenie termicznych NO.

$\mathrm{Na}$ podstawie danych pomiarowych dokonano obliczenia średniego względnego stopnia redukcji $\mathrm{NO}\left(\Delta_{\mathrm{NO}}\right)$, wykorzystując zależność:

$$
\Delta_{\mathrm{NO}}=\frac{\mathrm{NO}_{\text {sr.pom }}-\mathrm{NO}_{i n}}{\mathrm{NO}_{i n}} 100[\%]
$$

gdzie: $\mathrm{NO}_{s r, p o m}$ - średnia zawartość $\mathrm{NO}$ w gazie podczas spalania, $\mathrm{NO}_{i n}-$ zawartość NO w gazie na wlocie do komory spalania.

Ujemna wartość wyrażenia (1) wskazuje, że w danych warunkach dla określonego składu gazu, rodzaju paliwa oraz temperatury podczas spalania następuje obniżenie zawartości NO w gazach odlotowych. Na rysunku 3. pokazano wartości względnych stopni redukcji NO w zależności od temperatury oraz składu gazu dla różnych paliw. W przypadku braku pary wodnej w gazach wprowadzanych do komory spalania wzrost temperatury w zakresie $750-850^{\circ} \mathrm{C}$ pozytywnie wpływa na możliwość redukcji NO. Jedynie w przypadku węgla nr 1 w obu temperaturach $\left(750 \mathrm{i} 850^{\circ} \mathrm{C}\right)$ nie zaobserwowano obniżenia zawartości NO w spalinach. Z kolei w przypadku węgla $\mathrm{nr} 2$ oraz grafitu spalanie w temperaturze $850^{\circ} \mathrm{C}$ spowodowało ok. $2 \%$ redukcję NO. 


\section{Węgiel 1}

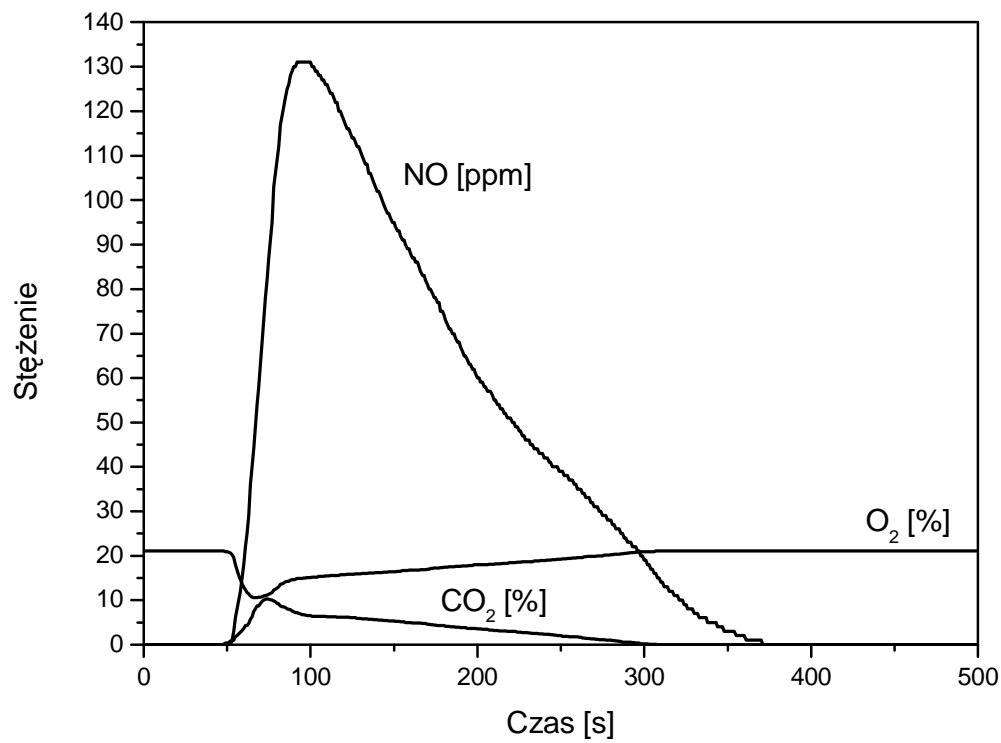

Grafit

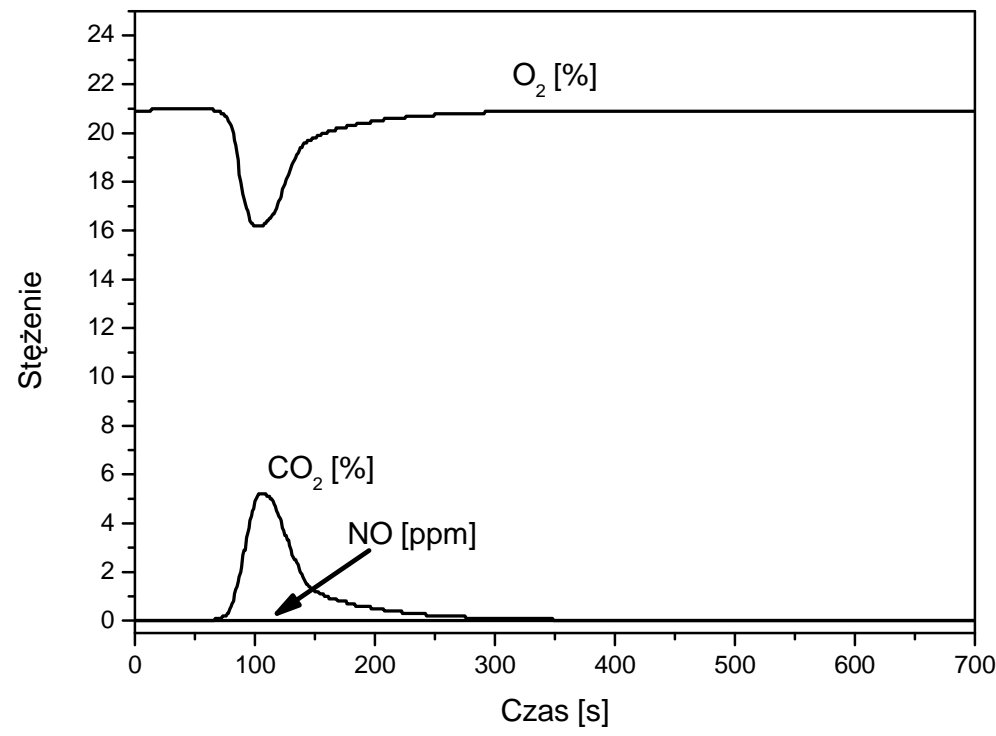

Rys. 2. Przebiegi czasowe zmian stężenia $\mathrm{NO}, \mathrm{CO}_{2}$ i $\mathrm{O}_{2}$ w spalinach dla wybranych testów (paliwo: węgiel nr 1 i grafit; $T=850^{\circ} \mathrm{C}$; spalanie w powietrzu)

Fig. 2. The waveforms of variation of the concentrations of $\mathrm{NO}, \mathrm{CO}_{2}$ and $\mathrm{O}_{2}$ in the flue gas for selected tests (fuel: coal no 1 and graphite; $T=850^{\circ} \mathrm{C}$; combustion in air) 


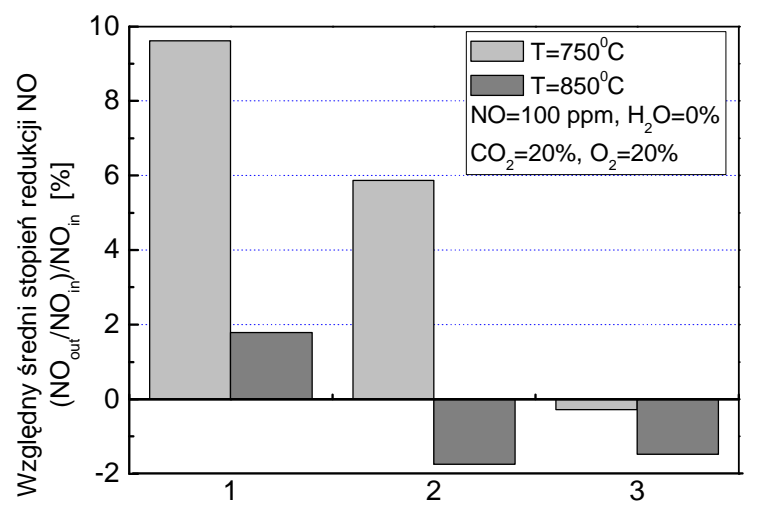

Rys. 3. Stopień redukcji NO w gazach w zależności od temperatury $\mathrm{w}$ komorze spalania oraz rodzaju spalanego paliwa; 1 - węgiel nr 1,2 - węgiel nr 2,3 - grafit

Fig. 3. Degree of NO reduction in the gas vs. temperature in the combustion chamber and fuel type; 1 - coal no 1 , 2 - coal no 2, 3 - graphite

Wyniki dla węgla (nr 1 i nr 2) zestawione na rys. 4. wyraźnie wskazują, że dla $10 \%$ stężenia $\mathrm{CO}_{2}$ i $10 \%$ zawartości $\mathrm{O}_{2} \mathrm{w}$ gazie stopień redukcji $\mathrm{NO}$ jest proporcjonalny do zawartości NO w gazie dolotowym. Odwrotną zależność zaobserwowano w przypadku grafitu, dla którego wzrost zawartości NO ze 100 do $300 \mathrm{ppm}$ spowodował ograniczenie średniego stopnia redukcji NO z ok. 6 do $4 \%$. Jak wynika $\mathrm{z}$ analizy uzyskanych danych, stopień redukcji NO jest bardzo uzależniony od zawartości $\mathrm{CO}_{2} \mathrm{w}$ gazie otaczającym płonące ziarna paliwa. Zwiększenie zawartości CO do poziomu $50 \%$ spowodowało prawie $10 \%$ redukcję NO. W przypadku spalania węgla (paliwo $\mathrm{nr} 1 \mathrm{i} \mathrm{nr} 2$ ) w atmosferze gazów zawierających przegrzaną parę wodną redukcja NO podczas testów prowadzonych w $950^{\circ} \mathrm{C}$ została zarejestrowana jedynie dla zwartości NO w gazach dolotowych wynoszącej $300 \mathrm{ppm}$. W odróżnieniu od węgla, spalanie grafitu spowodowało niewielkie (o ok. 3\%) ograniczenie emisji NO - pozytywny wpływ zarejestrowano zarówno przy zawartości NO w gazie wynoszącej 100 ppm, jak i $300 \mathrm{ppm}$.

Wyniki badań przedstawione na rys. 5. i przeprowadzone w temperaturze $850^{\circ} \mathrm{C}$ dla zawartości $\mathrm{NO} w$ gazie dolotowym wynoszącej $300 \mathrm{ppm}$ potwierdzają, że w odpowiednich warunkach jest możliwa redukcja stężenia NO w spalinach. Najwyższe wartości stopni redukcji obserwuje się w przypadku spalania węgla i w wysokich stężeniach $\mathrm{CO}_{2} \mathrm{w}$ gazie - uzyskane podczas testów wartości dochodziły do $8 \%$. Analiza odpowiednich zależności dla badanych rodzajów węgla potwierdziła ponadto, że stopień redukcji NO wzrasta przy wyższej zawartości $\mathrm{CO}_{2} \mathrm{w}$ gazie dolotowym oraz ulega ograniczeniu w przypadku wzrostu stężenia tlenu w otoczeniu płonącego paliwa. W przypadku grafitu stopnie redukcji NO są niższe niż ustalone dla węgla i nie przekraczają 2-4\%. Interesujące 


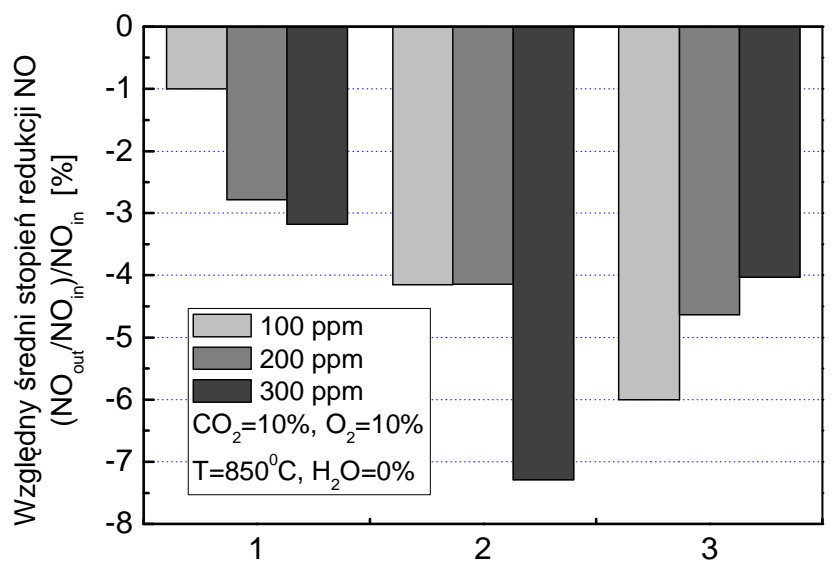

Rys. 4. Stopień redukcji NO w gazach w zależności od zawartości NO w gazie na wlocie do komory spalania; 1 - węgiel nr 1 , 2 - węgiel nr 2, 3 - grafit

Fig. 4. Degree of NO reduction in the gas vs. NO concentration at the inlet to the combustion chamber; 1 - coal no 1,2 - coal no 2, 3 - graphite

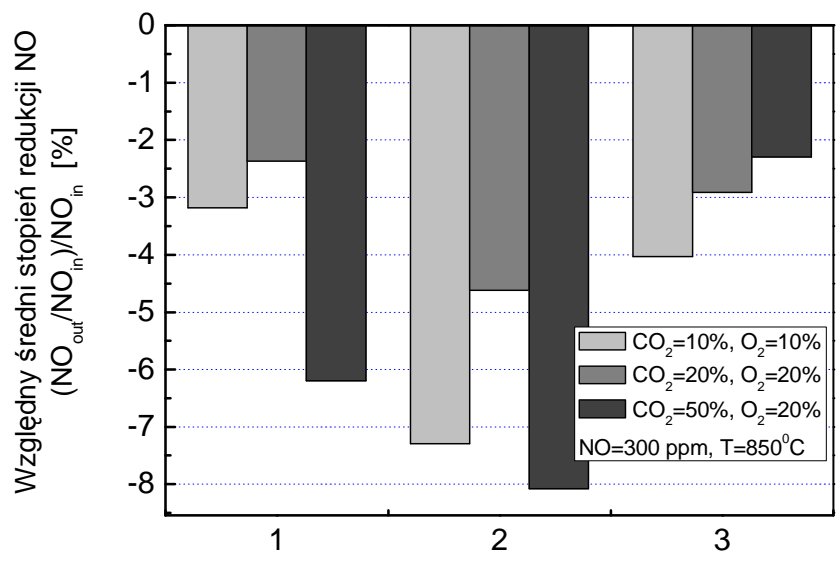

Rys. 5. Stopień redukcji NO w spalinach w zależności od zawartości $\mathrm{O}_{2}$ i $\mathrm{CO}_{2}$ w gazie na wlocie do komory spalania; 1 - węgiel nr 1,2 - węgiel nr 2, 3 - grafit

Fig. 5. Degree of $\mathrm{NO}$ reduction in the gas vs. $\mathrm{O}_{2}$ and $\mathrm{CO}_{2}$ concentration at the inlet to the combustion chamber; 1 - coal no 1 , 2 - coal no 2,3 - graphite

jest, że zwiększenie - w przypadku spalania grafitu - zawartości tlenu oraz $\mathrm{CO}_{2}$ w gazie dolotowym powoduje obniżenie średniej wartości stopnia redukcji NO 
(prawdopodobnie w efekcie zachodzenia reakcji Boudouarda). Hipotezę tę potwierdzają dane przedstawione na rys. 5 .

Wyniki badań oznaczania zawartości azotu w próbkach popiołu po spaleniu paliw wykazały śladowe zawartości azotu. W przypadku wszystkich badanych próbek zawartość tego pierwiastka nie przekraczała $0,01 \%$, potwierdzając, że podczas spalania azot zawarty w węglu przechodzi w całości do fazy gazowej.

\section{Podsumowanie}

Podczas spalania w atmosferze powietrza w zakresie temperatur $750-950^{\circ} \mathrm{C}$ nie stwierdzono tworzenia się termicznych tlenków azotu. Ustalono, że poziom emisji $\mathrm{NO}_{x}$ istotnie zależy od rodzaju paliwa, lecz dominującym składnikiem tworzącym $\mathrm{NO}_{x}$ jest $\mathrm{NO}$, który w każdym przypadku stanowi ponad $95 \% \mathrm{NO}_{x}$. Przebiegi czasowe zmian stężeń wybranych gazów potwierdzają występowanie swoistego „opóźnienia” w emisji azotu zawartego w paliwie podczas jego spalania. Maksimum emisji NO następuje zwykle po kilkunastu sekundach po zarejestrowaniu maksimum zawartości $\mathrm{CO}_{2}$ i odpowiadającej mu minimalnej zawartości tlenu. Analiza wyników badań zawartości NO w spalinach wskazuje, że w zakresie temperatur $750-950^{\circ} \mathrm{C}$ w pewnych warunkach, determinowanych stężeniem $\mathrm{CO}_{2}, \mathrm{NO}$ oraz $\mathrm{O}_{2}$ w komorze spalania, jest możliwa wyraźna, dochodząca nawet do $8 \%$, redukcja zawartości NO. Wniosek ten pozwala na pozytywne rokowania w aspekcie możliwości takiego kształtowania składu gazów i warunków hydrodynamicznych w przedpalenisku cyklonowym, aby możliwa była kontrola poziomu emitowanych z układu tlenków azotu $\mathrm{NO}_{x}$.

\section{Podziękowania}

Praca naukowa dofinansowana przez Narodowe Centrum Badań i Rozwoju, w ramach Strategicznego Programu Badań Naukowych i Prac Rozwojowych, pt. „Zaawansowane technologie pozyskiwania energii”, Zadanie Badawcze nr 2 „Opracowanie technologii spalania tlenowego dla kotłów pyłowych i fluidalnych zintegrowanych z wychwytem $\mathrm{CO}_{2}$ ”, umowa nr SP/E/2/66420/10.

\section{Literatura}

[1] Zarzycki R., Kratofil M., Pawłowski D., Ścisłowska M., Kobyłecki R., Bis Z.: Analiza spalania pyłu węglowego w przedpalenisku cyklonowym, Polityka Energetyczna, 16 (2013), 325-337.

[2] Zarzycki R., Kratofil M., Pawłowski D., Ścisłowska M., Kobyłecki R., Bis Z.: Analiza wyników obliczeń numerycznych przepływu pyłu węglowego oraz gazu w palenisku cyklonowym, Polityka Energetyczna, 16 (2013), 301-312.

[3] Zarzycki R., Kratofil M., Pawłowski D., Ścisłowska M., Kobyłecki R., Bis Z.: Układ podawania paliwa do przedpaleniska cyklonowego, Polityka Energetyczna, 16 (2013), 313-324. 
[4] Czakiert T.: Emisje zanieczyszczeń gazowych w procesie spalania węgla brunatnego w cyrkulacyjnej warstwie fluidalnej $\mathrm{w}$ atmosferze wzbogaconej tlenem, praca doktorska, Politechnika Częstochowska, Częstochowa 2004.

\section{FORMATION AND REDUCTION OF NITRIC OXIDE UNDER OXYCOMBUSTION CONDITIONS}

\section{S u m m a r y}

The article presents the results of the investigation of the possibility to reduce NO in conditions similar to those characteristic for the oxycombustion process. Analysis of the waveforms of variation of the concentrations of $\mathrm{NO}, \mathrm{CO}_{2}$, and $\mathrm{O}_{2}$ in fuel gas during fuel oxidation was carried out. Furthermore, the conditions that favour the reduction of No concentration in inlet gases were determined. It was found that in the temperature range of $750-950^{\circ} \mathrm{C}$ no thermal $\mathrm{NO}$ is formed during the combustion in air. However, the results obtained for the different gas composition indicated that under certain conditions it is possible to reduce up to $10 \%$ of the initial NO concentration in the inlet gas. The analysis of nitrogen content in the fuel and ash samples after combustion process showed that just trace content of $\mathrm{N}$ was found (in case of all tested samples the nitrogen content was under $0.04 \%$ ), it is confirmed that during combustion the majority of nitrogen is transformed to the gas phase.

Keywords: oxycombustion, cyclone pre-furnace, nitric oxide

DOI: $10.7862 / \mathrm{rm} .2015 .10$

Otrzymano/received: 15.09.2014 r.

Zaakceptowano/accepted: 10.01.2015 r. 